\title{
Dental treatment for people with challenging behaviour: general anaesthesia or sedation?
}

\author{
M. C. G. Manley, ${ }^{1}$ A. M. Skelly, ${ }^{2}$ and A. G. Hamilton, ${ }^{3}$
}

The dental care of people with severe learning disability and challenging behaviour presents many problems. The maintenance of oral health by regular examination, prevention and treatment may be difficult because of the limitations in patient cooperation. In many cases the diagnosis of orofacial pain may need to be discounted as a cause of uncharacteristic and sometimes aggressive behaviour. In such cases the use of general anaesthesia for examination and treatment would seem to be the obvious option but this strategy has limitations. This paper undertakes a focused review of sedation techniques as an alternative to general anaesthesia in the treatment of people with challenging behaviour. The use of novel techniques of sedation combining intravenous with oral or intranasal routes is described with patients treated in a community dental health centre. All patients had previously received treatment using general anaesthesia. The techniques described proved effective and safe for use in the primary care setting.

$\mathrm{T}$ he provision of comprehensive dental care for people with disabilities can present difficulties. It has been shown that around $20 \%$ of people with a disability needed a general anaesthetic to receive dental treatment. ${ }^{1}$ In the present climate society requires that health professionals strive for equal access to and equal standards of care for all people. ${ }^{2}$ The dental profession should look carefully at its strategies for the treatment of people with disability.

While general anaesthesia is a useful facility and, indeed, essential in certain cases, it is not without problems. For example, unless full intubation facilities are available, restora-

${ }^{1}$ Senior Dental Officer-Special Needs, ${ }^{3}$ Consultant Anaesthetist, East Kent Community Dental Service, Canterbury Health Centre, 26 Old Dover Rd,

Canterbury, Kent CT1 $3 \mathrm{JH} ;{ }^{2}$ Senior Lecturer and

Consultant in Dental Sedation, Department of Sedation and Special Care Dentistry, The Guy's,

King's, and St.Thomas Dental Institute, Guy's

Campus, St Thomas Street, London SE1 9RT

Correspondence to: M. C. G. Manley, Canterbury

Health Centre, 26 Old Dover Rd, Canterbury, Kent

CT1 $3 J \mathrm{H}$

REFEREED PAPER

Received 09.04.99; accepted 22.11.99

() British Dental Journal 2000; 188: 358-360 tive treatment is difficult to provide and treatment may be limited to extractions only. Even when the length and range of treatment is extended by the use of tracheal intubation, it compares poorly with that available to a conscious individual. Periodontal or endodontic treatment requiring multiple visits and other complex or time-consuming

\section{In brief}

- Sedation is an effective and safe alternative to general anaesthesia.

- Sedation enables diagnosis and treatment for people with challenging behaviour in the primary care setting.

- The use of sedation extends the range of treatment options for people with challenging behaviour.

- People who are medically compromised can be treated using sedation techniques.

- The use of sedation can increase the availability of treatment for people with disability compared with general anaesthetic. procedures cannot be provided ideally under general anaesthesia. Therefore the person with a disability often remains disadvantaged compared with his abler counterparts.

Limitations in the provision of dental treatment under general anaesthesia may result not only in impaired dental health and aesthetics, but also present difficulties to carers and dentists faced with behaviour changes caused by pain from oro-facial pathology. This is particularly a problem for those with poor communication. Self injury or aggressive physical violence may result from the individuals' inability to indicate the source of their discomfort.

It must be recognised that in proper conditions, with appropriately trained, qualified and experienced staff, the risk to patients receiving treatment under general anaesthesia is small ${ }^{3}$ unless there are complicating medical factors. ${ }^{4}$ However dentists, anaesthetists and carers may be faced with the difficult decision to proceed with general anaesthesia for diagnostic purposes in the absence of any clear symptoms. In addition, for those with severe learning disability and challenging behaviour, the ethics of regular use of general anaesthesia for a routine examination and scale and polish is questionable.

The place of conscious sedation

In view of the fact that a number of reports, ${ }^{5-7}$ have encouraged the use of conscious sedation as an alternative to general anaesthesia, this review considers whether these techniques can be applied in difficult-to manage cases such as treating people with severe learning disability or challenging behaviour. Sedation is considered to be more flexible than general anaesthesia and is also more likely to be available in the primary care setting widening treatment options.

\section{Problems in providing sedation for people with disability}

Many of the difficulties in providing sedation for this group lie in the areas of cooperation, communication and cognitive ability. For example an adult with challenging behaviour may not be sufficiently cooperative to allow 
venepuncture prior to the administration of intravenous drugs. A person with severe learning difficulty may not be able to understand or comply with the need to breathe continuously through the nose as a requirement of inhalation sedation. Verbal communication may not be possible as a clinical sign of conscious sedation when using intravenous sedation. It may be for these and other reasons that the standard strategy of care for such patients is the provision of treatment under general anaesthetic. This paper sets out to challenge this assumption.

\section{Evidence from the literature}

Healy et al. examined the use of local anaesthetic and intravenous diazepam, as an alternative to general anaesthesia, and found the operating conditions acceptable in $80 \%$ of cases; ${ }^{8}$ the patients were adults with mildmoderate learning disability. Manford and Roberts showed the successful use of relative analgesia as an alternative to the use of general anaesthesia in the treatment of young handicapped patients. ${ }^{9}$ Malamed et al. reviewed retrospectively 96 adults with impairments treated using a combination of intravenous drugs (diazepam, midazolam, meperidine and pentazocine) and in a small number of cases (14 uncooperative patients) the intravenous drugs were combined with intramuscular midazolam plus meperidine. ${ }^{10}$ Four patients could not be treated using these techniques and were referred for general anaesthesia. A similar drug combination was also used by Jakobs et al. with an adult group. ${ }^{11}$ Silver et al. showed the effective use of oral midazolam in 31 patients aged 3-18 years. ${ }^{12}$ The children were physiologically and neurologically handicapped and treatment success varied from $60-75 \%$ depending on dosage used. Benzodiazepines have been traditionally used in children, however oral ketamine was successfully used by Rosenberg in the case of an 'extremely combative mentally handicapped female.' ${ }^{13}$ Combinations of oral meperidine and promethazine with inhalation nitrous oxide/ oxygen sedation have also been used in medically/physically/mentally compromised children as reported by Haney et al. ${ }^{14}$ OeiLim et al. reported on the use of intravenous propofol for the dental treatment of adults with impairments as an alternative to inhalation sedation. ${ }^{15}$ The authors concluded that the quality and ease of sedation was good (in all but two cases) using intravenous propofol and the use of propofol was an acceptable alternative to inhalation sedation. Oei-Lim et al. used propofol given by a computer controlled infusion system in a further study on adults with impairments. ${ }^{16}$ The study group comprised 89 patients who could not be treated using inhalation sedation, their median age was 29 years and all were medically fit (ASA I or II). The quality of sedation was good or excellent in $88 \%$ of cases and it was concluded that this technique can provide safe and satisfactory sedation for this group of patients. In a double blind crossover study Stephens et al. compared intravenous midazolam against propofol in a group of patients with impairments of age range 5 to 26 years. ${ }^{17}$ Eighteen cases were involved in the study and an anaesthetist administered the drugs by continuous infusion. The authors concluded that propofol had certain advantages over midazolam used in this way, particularly the rapid recovery from sedation. Van der Bijl et al. used a combination of propofol by continuous infusion and midazolam bolus with an ASA IV 21-year-old patient with learning disability. ${ }^{18}$ The treatment provided was dental extractions and the patient was well sedated throughout the procedure, with no significant cardiovascular or respiratory effect. Two years later the same patient was sedated for further dental treatment using a propofol infusion. ${ }^{19}$ The patient remained well throughout the procedure and no adverse effects were experienced. The same authors also reported the successful use of intravenous midazolam in a 29-year-old female patient with involuntary movements. ${ }^{20}$ Two studies were carried out by Fukata et al. using midazolam administered intranasally combined with nitrous oxide/oxygen inhalation sedation. ${ }^{21,22}$ The patients selected were those with learning disability with age range from 4 to 23 years. The first study (21 cases of patients with learning disability) showed a successful treatment outcome in $70 \%$ of cases. The second study (43 cases with challenging behaviour) compared the varying doses of $0.2 \mathrm{mg} / \mathrm{kg}$ and $0.3 \mathrm{mg} / \mathrm{kg}$ intranasal midazolam to deter- mine the appropriate concentration for the use of this drug by this route. It was concluded that there were no clinical benefits using the higher concentration and therefore $0.2 \mathrm{mg} / \mathrm{kg}$ was recommended.

Although the evidence presented here is not extensive, it clearly shows that conscious sedation techniques can be successfully and safely used in the treatment of people with disability. It is of particular note that conscious sedation was successfully used in a seriously medically compromised case. ${ }^{18,19}$ The use of a combination of intravenous drugs, and different routes of administration (eg intranasal) suggest that for this group there are particular problems and that a more flexible approach is required to that used when sedating people who do not have a disability.

\section{A novel approach in clinical practice}

In order to address these problems, techniques have been developed for the treatment of difficult-to-manage patients with challenging behaviour at the Canterbury Community Health Centre Dental Department.

Before the introduction of these new techniques, treatment was already being provided successfully under intravenous midazolam sedation for very anxious individuals. This sedation was provided by an experienced operator-sedationist assisted by a trained and qualified dental nurse. However this was not suitable for many patients with challenging behaviour or severe learning disability whose behaviour prevented the safe placement of a cannula. The techniques described here were designed to allow dental treatment to be provided for such patients who had previously received all their dental treatment under general anaesthesia.

Midazolam is administered either orally, in a preferred drink, or intranasally as a fine aerosol delivered from a $2 \mathrm{ml}$ syringe through a spray nozzle. Oral midazolam is used in a dose of $20 \mathrm{mg}$ compared with $10 \mathrm{mg}$ for the intranasal route. The oral or nasal medication provides sufficient sedation to allow cannulation and appropriate monitoring to be put in place before proceeding to intravenous sedation. Intravenous midazolam is titrated to each patient's response according to the manufacturer's Data Sheet. $^{23}$ 
A review of the introduction and development of this practice over a 6-year period is presented here. A retrospective audit of 124 patient records was made.

The oral or intranasal route alone was used for seven and ten patients respectively. When used in combination with the intravenous route, oral midazolam was used for 44 and intranasal midazolam for 21 individuals. The mean number of treatment visits per patient was two, and, over the 6-year period, midazolam was used orally 102 times and intranasally on 62 occasions. During the period audited only four patients originally selected for midazolam sedation could not be treated using one of these techniques and required referral for general anaesthesia. As the Centre is also able to provide intravenous sedation with propofol for suitable cases, when a consultant anaesthetist is present, the overall number of patients referred for general anaesthesia is much reduced by the availability of a comprehensive range of sedation techniques.

The novel approach of a combination of oral/intranasal and intravenous routes has shown that sedation with a single drug can be effectively and safely employed in a primary care setting for difficult-to-manage patients.

The use of oral midazolam is already well established in medicine ${ }^{24}$ and nursing 25 and it has also been shown to be effective in dentistry. ${ }^{26}$ Intranasal midazolam has also been found to be beneficial within nursing ${ }^{27}$ and in the dental treatment of people with learning disability. ${ }^{21,22}$

It should be noted that when midazolam is administered by either of the above routes in the United Kingdom it is used without a licence. This is permissible provided that the supplier (usually the local pharmacy) is made aware of the proposed unlicensed use of any drug. ${ }^{28}$ Specific attention should be drawn to the off-licence use of midazolam on the patient's consent/agreement to treat form and the sedationist must be up to date with current evidence supporting the use of the drug in these ways. A practitioner who chooses to use a drug outside the limits of its licence must take full responsibility for this action. If the above recommendations are followed, good clinical practice is ensured. ${ }^{29,30}$

\section{Conclusion}

This review shows that sedation can be used both safely and effectively for people with disabilities. Conscious sedation techniques must be adapted to the special needs of this patient group and clinicians may need to be flexible in their approach to the problems presented. We suggest, however, that the techniques described in this paper should only be used by practitioners who have had appropriate experience of both intravenous sedation and in the care of people with disabilities. In order to widen access to a more comprehensive range of treatment modalities for this section of our population, further training of dentists and their teams is necessary. ${ }^{31}$

1 Holland T J, O'Mullane D M. The organisation of dental care for groups of mentally handicapped persons. Community Dent Health 1990; 7: 285-293.

2 Court Report of the Committee on Child Health. Fit for the future. London: HMSO, 1976.

3 Worthington L M, Flynn P J,Strunin L. Death in the dental chair: an avoidable carastrophe? $\mathrm{Br} \mathrm{J}$ Anaesthesia 1998; 80: 131-132.

4 Moore R S, Hobson P. A classification of medically handicapping conditions and the health risks they present in the dental care of children. J Paediatr Dent 1989; 5: 73-83.

5 Poswillo D. General anaesthesia,sedation and resucitation in dentistry. Report of an Expert Working Party for the Standing Dental Advisory Committee. London Department of Health, 1990.

6 Press release and response to reports on general anaesthesia, sedation and resucitation in dentistry. Department of Health, 1991.

7 Report of a Working Party on Training in Dental Anaesthesia. Wylie, The Royal College of Surgeons of England, 1978.

8 Healey T J, Edmonson H D, Hall N. Sedation for the mentally handicapped patient. Anaesthesia 1971; 26: 308-310.

9 Manford M L M, Roberts G J. Dental treatment in young handicapped patients. An assessment of relative analgaesia as an alternative to general anaesthesia. Anaesthesia 1980; 35: 1157-1168.

10 Malamed S F, Gottschalk H W, Mulligan R, Quinn C L. Intravenous sedation for conservative dentistry for disabled patients. Anaesthesia Progress 1989; 36: 140-142.

11 Jakobs W, Lipp M, Daublander M, JakobsHannegrefs E. Dental treatment of handicapped patients with conscious sedation. Anaesthesia Progress 1989; 36: 144-145.

12 Silver T, Wilson C, Webb M. Evaluation of two doses of oral midazolam as a conscious sedation for physically and neurologically compromised pediatric dental patients. Pediatr Dent 1994; 16: 350-359.

13 Rosenberg M. Oral ketamine for deep sedation of difficult-to-manage children who are mentally handicapped: case report. Pediatr Dent 1991; 13: 221-223.

14 Haney K L, McWhorter A G, Seale N S. An assessment of the sucess of meperidine and promethazine sedation in medically compromised children. ASDC J Dent Children 1993; 60: 288-294.

15 Oei-Lim L B. ,Vermeulen-Cranch D E, Bouvy Berends E M. Conscious sedation with propofol in dentistry. Br Dent J 1991; 170: 340-344.

16 Oei-Lim L B, Kalkman C J, Makkes P C, Ooms W G, Hoogstraten J. Computer controlled infusion of propofol for conscious sedation in dental treatment. Br Dent J 1997; 183: 204-208.

17 Stephens A J, Sapsford D J, Curzon M E J. Intravenous sedation for handicapped dental patients: a clinical trial of midazolam and propofol. Br Dent J 1993; 175: 20-25.

18 Van der Bijl., Roelofse J A. Propofol and midazolam for conscious sedation in a mentally retarded dental patient. Anaesthesia Progress 1992; 37: 37-39.

19 Van der Bijl, Roelofse J A. Propofol for sedation in a mentally retarded dental patient. Anaesthesia Progress 1994; 41: 81-82.

20 Van der Bijl P, Roelofse J A. Conscious sedation with midazolam in a patient with a spastic nerve muscular disorder - a case report. Annals of Dent 1994; 53: 37-38.

21 Fukuta O, Braham R L, Yanase H, Atsumi N, Kurosu K. The sedative effect of intranasal midazolam in the dental treatment of patients with mental disabilities Partl - The effect of a 0.2 $\mathrm{mg} / \mathrm{kg}$ dose. J Clin Pediatr Dent 1993; 17: 231-237.

22 Fukuta O, Braham R L, Yanasa H, Kurosu K. The sedative effect of intranasal midazolam in the dental treatment of patients with mental disabilities. Part 2 - Optimal concentrations of intranasal midazolam. J Clin Paediatr Dent 1994; 18: 259-265.

23 ABPI Compendium of Data Sheets. London: Data Pharm Publications, 1998-9: 1132.

24 McCluskey A, Meakin GH. Oral administration of midazolam as a premedicant for paediatric daycase anaesthesia. Anaesthesia 1994; 49: 782-785.

25 Taiwo B, Flowers B, Zoltie N. Reducing children's fear when undergoing painful procedures. Archives of Emergency Med 1992; 9: 306-309.

26 O’Boyle C A, Harris D, Barry H, Mccreary C, Bewley A, Fox E. Comparison of midazolam by mouth and diazepam i.v. in outpatient oral surgery. Br J Anaesthesia 1987; 59: 746-754.

27 Adrian E R. Intranasal Versed: The future of pediatric conscious sedation. Pediatr Nurs 1994; 20: 287-291.

28 Dental Practitioners' Formulary. Prescribing for dental surgeons. BDA, BMA, RPSGB. London 1998-2000. pvii.

29 Pickles $\mathrm{H}$. The use of unlicensed drugs. $\mathrm{Br} \mathrm{J}$ Health Care Management 1996; 2: 656-658.

30 Editorial. Unlicensed drug administration Anaesthesia 1995; 50: 189-190.

31 Maintaining standards-guidance to dentists on professional and personal conduct. London: General Dental Council. Revised November 1998. Amended May 1999. 